\title{
Alunos com necessidades educacionais especiais (NEEs): avaliar para o desenvolvimento pleno de suas capacidades
}

\author{
TEREZA LIDUINA GRIGÓRIO FERNANDES* \\ TANIA VICENTE VIANA**
}

\section{RESUMO}

Um dos maiores desafios da escola é identificar e desenvolver as capacidades de alunos com Necessidades Educacionais Especiais (NEEs). A avaliação educacional diagnóstica permite conhecer melhor esses aprendizes, identificando suas NEEs, motivaçóes, hábitos, conhecimentos, níveis de autoestima, facilidades ou dificuldades em determinadas áreas do saber ou do fazer. A avaliação da aprendizagem também pode contribuir ativamente nesse sentido, de modo a incentivar esse aluno a aprender e a se desenvolver. A forma tradicional de avaliar não considera seus limites e potencialidades, colaborando para que fique retido por não aprender, o que é injustificado, incoerente e inconstitucional. Embora a avaliação diagnóstica tenha apresentado significativa evolução na Educação Especial, progredindo da visão clínicomédica para a concepçâo de inclusão educacional e social, ainda persistem dificuldades na elaboração de instrumentos para uma avaliação da aprendizagem capaz de contribuir para o crescimento e a autonomia desses alunos. Este trabalho, por meio de uma revisão da literatura especializada, intenciona refletir sobre a contribuição da avaliação educacional, nas áreas do

* Mestranda em Educação pela Faculdade de Educação da Universidade Federal do Ceará (FACED/UFC). Coordenadora do Centro de Atendimento ao Surdo (CAS) (tereza.ufal@yahoo.com.br).

** Professora adjunta do Departamento de Fundamentos da Educação da FACED/UFC (taniaviana@ufc.br). 
diagnóstico e da aprendizagem, para o desenvolvimento pleno desse alunado.

Palavras-chave: educação especial, avaliação da aprendizagem, repetência, inclusão social.

\section{RESUMEN}

Uno de los mayores desafíos de la escuela es identificar y desarrollar las capacidades de los alumnos con Necesidades Educativas Especiales (NEEs). La evaluación educativa diagnóstica permite conocer mejor a estos aprendices, al identificar sus NEEs, motivaciones, hábitos, conocimientos, sus niveles de autoestima, facilidades o dificultades en determinadas áreas del saber o del hacer. La evaluación del aprendizaje también puede contribuir activamente en este sentido, con el fin de incentivar al alumno a aprender y a desarrollarse. La forma tradicional de evaluación no considera sus limitaciones y potencialidades, obstaculizando el aprendizaje y provocando, eventualmente, que el alumno repita de año, lo que es injustificado, incoherente e inconstitucional. Aunque la evaluación diagnóstica haya presentado progresos significativos en la Educación Especial, al pasar de una visión clínico-médica hacia una concepción de inclusión educativa y social, todavía existen dificultades en la elaboración de instrumentos para una evaluación del aprendizaje que sea capaz de contribuir con el crecimiento y la autonomía de estos alumnos. Este trabajo, a través de una revisión de la literatura especializada, reflexiona sobre la contribución de la evaluación educativa en las áreas del diagnóstico y del aprendizaje, para el pleno desarrollo de los alumnos.

Palabras clave: educación especial, evaluación del aprendizaje, repitencia, inclusión social.

\section{ABSTRACT}

One of the biggest challenges school faces is identifying and developing the capacities of students with special educational needs. The diagnostic evaluation in education allows one to know these students better, identifying their special educational needs, motivations, habits, knowledge, self-esteem levels, facilities or difficulties in certain areas. The learning evaluation can also actively contribute in that sense to motivate students to learn and to develop themselves. The traditional way of evaluating does not take into account their limits and potentialities, contributing to fail them when they do not learn, which is unjustified, incoherent and unconstitutional. Although the diagnostic evaluation has presented significant evolution in Special Education, progressing from the clinical vision to the conception of education and social inclusion, some difficulties remain in building specific tools for a learning evaluation capable to contribute to the development and autonomy of those students. This paper, through a revision of specialized literature, intends to reflect about the contribution of the evaluation in education, in the areas of diagnosis and learning, to the full development of those students. Keywords: special education, learning evaluation, failing, social inclusion. 


\section{INTRODUÇÃO}

A valorização crescente atribuída à avaliação da aprendizagem vem gerando, nas últimas décadas, a permanente necessidade de mudanças nas práticas avaliativas por parte de técnicos e educadores. Nessa perspectiva, convém recordar que é mais importante procurar compreender os aspectos subjacentes do desempenho acadêmico discente, como forma de proporcionar investigaçôes e intervençôes mais eficientes, do que simplesmente registrar seu sucesso ou fracasso escolar (Hadji, 2001; Hoffmann, 2001; Luckesi, 2005).

Os professores, por estarem em contato direto com os alunos em sala de aula, são os profissionais da educação mais indicados para fazer uma avaliação diagnóstica. Podem observar - formal e informalmente - as atividades e comportamentos revelados no cotidiano, e ainda sinalizar capacidades gerais e específicas.

A sala de aula necessita se consolidar, então, como espaço para a identificação e progresso das diversas habilidades humanas. Deve-se considerar a multiplicidade de situaçóes em que a inteligência se manifesta, de acordo com as necessidades básicas do estudante, para seu aperfeiçoamento como ser humano integral. Nesse contexto, importa assinalar que também a pessoa com deficiência pode ser definida em função de suas competências, contribuindo, de forma relevante, para a evolução do saber. Beethoven, por exemplo, compôs sua famosa Nona Sinfonia praticamente imerso em profundo silêncio, pois já se encontrava bastante desprovido de audição (Alencar, 2003; Brasil, 1999).

Diante dos avanços nas mais diversas áreas do conhecimento, característicos da sociedade contemporânea, as exigências educacionais vêm sendo modificadas (Pozo, 2002). A população se depara com condiçóes de maior acesso a informaçáo, estímulos visuais e desafios; como as famílias estão menores, os genitores podem dedicar mais tempo e atenção ao desenvolvimento intelectivo dos filhos. Por outro lado, os empregos, de maneira geral, exigem mais esforço mental, necessitando, assim, que as pessoas aprimorem seus conhecimentos.

As próprias atividades de lazer, com o advento de equipamentos eletrônicos e de comunicação, como videogames e computadores, demandam acentuado poder de concentração e raciocínio, cooperando para a estruturação de habilidades cognitivas múltiplas. Dessa forma, não raro as crianças utilizam o computador, assistem à televisão e escutam música simultaneamente, exercitando memória e atenção difusa, com a decorrente capacidade de sustentar a concentração em várias atividades concomitantes; mesmo o lazer solicita elementos educativos, pois se faz necessário estar atualizado e bem informado em situaçóes de convívio social. 
Como consequência, um novo modelo de escola deve possibilitar a exposição e o desenvolvimento das atuais motivaçóes infantis. Os alunos estão mais interessados em entender processos do que em memorizar dados, e as formas de socialização permitidas pela revolução da informática ampliam o universo do indivíduo, colocando-o em contato com diferentes culturas, idiomas e costumes (Pozo, 2002).

A literatura especializada argumenta ser a inteligência encontrada em todas as raças e gêneros, bem como em todas as camadas sociais e econômicas. A incidência de altas habilidades/superdotação ${ }^{1}$, por exemplo, ocorre de modo aleatório, numa estimativa de 3 a $5 \%$ da população mundial, em grupos privilegiados ou marginalizados socialmente. Uma análise histórica revela que o conceito de inteligência passou por modificaçóes associadas sobretudo às tecnologias características de cada época. Nos dias fluentes, apreciam-se, por sua vez, as capacidades relativas ao manejo da informática. Dessa forma, diferentes expressóes da inteligência são valorizadas ou depreciadas conforme o contexto sócio-histórico (Alencar, 1986; Brasil, 1999).

A oferta de ambientes educacionais ricos em estímulos favorece, indubitavelmente, o desenvolvimento democrático da inteligência. Considerando a necessidade de uma política educacional que favoreça, de modo geral, a ampla evoluçáo das capacidades de todos os alunos, este trabalho objetiva refletir sobre a influência da avaliação da aprendizagem para o desenvolvimento pleno do ser humano, especialmente no que concerne às pessoas com Necessidades Educacionais Especiais (NEEs).

Pessoas com NEEs apresentam, normalmente, impedimentos de longo prazo, de natureza física, mental, intelectual ou sensorial, que, em interação com diversas barreiras, podem restringir sua participação efetiva na escola e na sociedade. Acerca desse alunado, Magalhães (2003) esclarece ser composto por: alunos com dificuldades de aprendizagem, problemas de comportamento, deficiência física sensorial (cegos, surdos e surdos-cegos), deficiência física não-sensorial (paralisia cerebral, por exemplo), deficiência mental, deficiências múltiplas. Somam-se a este grupo os alunos com altas habilidades (superdotação) que necessitam de currículo diferenciado por sua superior capacidade de aprendizagem.

\footnotetext{
${ }^{1}$ Pessoas com altas habilidades/superdotação, de acordo com técnicos do Ministério da Educação (MEC), demonstram potencial elevado em qualquer uma das seguintes áreas, isoladas ou combinadas: intelectual, acadêmica, liderança, psicomotricidade e artes. Também apresentam elevada criatividade, grande envolvimento na aprendizagem e na realização de tarefas em áreas de seu interesse (Brasil, 2008).
} 
Cumpre mencionar que as pessoas com transtornos invasivos do desenvolvimento (autismo) ${ }^{2}$ e transtorno de déficit de atenção e hiperatividade (TDAH) também integram esse conjunto de aprendizes que necessitam de uma assistência educacional diferenciada.

O aluno com NEEs - como qualquer outra criança, jovem ou adulto - também tem direito a desenvolver o seu potencial, assegurado por legislação nacional e internacional, podendo colaborar de modo ativo para o progresso artístico e científico de sua nação. Importa lembrar que as altas habilidades/superdotação podem se manifestar associadas a outras NEEs, sendo encontradas, igualmente, em pessoas com dificuldades de aprendizagem, problemas de comportamento, deficiência, autismo e TDAH (Alencar, 2003; Brasil, 1999).

Avaliaçóes diagnósticas para verificar a qualidade da aprendizagem constituem uma alternativa viável e necessária para estimular não somente o aprendizado, mas também a inteligência dos alunos. Desse modo, pode-se expandir esse benefício para a população pertencente a segmentos socioeconômicos desfavorecidos e colaborar, cientificamente, para uma visão mais completa da pessoa com NEEs, analisada para além de suas limitaçóes (Anastasi; Urbina, 2000; Lage et al., 1999).

Este trabalho, por meio de uma revisão da literatura especializada, intenciona refletir sobre a contribuição da avaliação educacional, nas áreas do diagnóstico e da aprendizagem, para o desenvolvimento pleno desses alunos.

\section{DA AVALIAÇÃO DIAGNÓSTICA À AVALIAÇÃO DA APRENDIZAGEM}

A avaliação diagnóstica - como processo pedagógico, psicológico e psicopedagógico - tem avançado de modo substancial nas últimas décadas. Inicialmente, costumava ser realizada apenas por especialistas da área médica; com as exigências do desenvolvimento científico, houve um redimensionamento gradual no sentido do diagnóstico interdisciplinar a partir da década de 1970. Portanto, a tendência atual consiste em adotar o diagnóstico como um processo abrangente, também interligado às investigaçóes sobre aprendizagem. Nesse panorama, questiona-se a qualificação do docente para esse propósito, seja referente ao aluno comum ou ao que apresenta NEEs (Fernández, 1991; Weiss, 1997).

\footnotetext{
${ }^{2} \mathrm{O}$ autismo se caracteriza por comprometimento nas áreas de interação social, comunicação e comportamento. $\mathrm{O}$ autista demonstra: conduta alheia ao ambiente social; tendência a vocalizações e movimentos repetitivos; resistência a alterações na rotina (Herrero, 2000; Lage, 2003).
} 


\subsection{O diagnóstico pedagógico}

O diagnóstico como processo pedagógico permite conhecer os alunos individualmente, em grupos e em família; as particularidades reais do aprendente, suas necessidades, motivos, capacidades, hábitos, habilidades, conhecimento, autoestima, potencialidades e diferenças. O diagnóstico pedagógico deve-se inserir numa perspectiva ampla, oferecendo informaçóes sobre o contexto do aluno e sua consequente influência para o progresso de seu aprendizado. Dessa maneira, a compreensão global da aprendizagem e seus desvios solicita uma análise não somente do sujeito, mas da qualidade das relaçóes que ele estabelece com a escola, a família e a sociedade (Fernández, 1991; Weiss, 1997).

Essa concepção contrasta com o tradicional modelo médico-psicólogico, que costuma enfatizar os aspectos patológicos em detrimento dos saudáveis, bem como as dificuldades em vez das potencialidades. A aplicação desse modelo na educação não oferece, ao professor, muitas alternativas na execução do planejamento das atividades de ensino. Ao contrário, funciona como um rótulo, que induz a uma predisposição negativa: o educador passa a exigir menos do aluno, descrente de seu potencial; exime-se da responsabilidade de auxiliá-lo a superar suas dificuldades, supostamente acreditando, dessa forma, que intervençóes educativas não redundarão em qualquer êxito (Magalhães, 2003).

O diagnóstico se converteu em um fim, afastando-se cada vez mais da intervenção, que deveria ser seu único e verdadeiro objetivo. Os testes de inteligência ou rendimento acadêmico apresentaram, de fato, um efeito deletério, especialmente para o alunado com NEEs. A classificação, legitimada por valores supostamente objetivos como o Quociente de Inteligência $(\mathrm{QI})^{3}$, discriminou e segregou os mais e os menos capazes, enfatizando os déficits de qualquer pessoa - com ou sem NEEs - ao invés de ressaltar sua capacidade de realização (Anastasi; Urbina, 2000; Fernández Cabezas, 2000; Magalhães, 2003).

Desse modo, ainda nos dias atuais,

[...] observamos que a tarefa diagnóstica, tanto em nível institucional como privado, carece de operatividade, transformando-se muitas vezes em um oráculo que determina discriminatoriamente o futuro intelectual de uma criança, quan-

\footnotetext{
${ }^{3} \mathrm{O}$ QI intenciona classificar a inteligência por meio da quantificação do intelecto. Atualmente, é visto como uma medida de desempenho educacional apta a identificar apenas uma parcela da inteligência, de natureza acadêmica; isso ocorre porque esses testes investigam habilidades verbais e numéricas usualmente associadas ao desempenho acadêmico (Anastasi; Urbina, 2000; Viana, 2005).
} 
do não em um calmante de ansiedades e em disfarce de ineficiência de certos profissionais e docentes, a partir da pseudotranquilidade que outorgam os rótulos do tipo: "debilidade mental", "problema de aprendizagem de ordem orgânica", "hipercinesia", etc. Ainda no melhor dos casos pode chegar a transformar-se em mais uma marca, para um indivíduo a quem permanentemente se examina, se mede, e a quem poucos escutam. (Fernández, 1991, p. 24)

Uma avaliação diagnóstica adequada deve esclarecer os aspectos individuais, mas não pode negligenciar os sociais. Convém assinalar que mesmo diante de limitaçóes particulares, inclusive de natureza genética e/ou biológica, como no caso do deficiente, um melhor desenvolvimento pode ser obtido como resultado de condiçôes favoráveis e estimulaçóes adequadas do meio físico e social (Fernández, 1991; Weiss, 1997).

A deficiência, por si própria, não se encontra estreitamente associada a dificuldades de aprendizagem. Por outro lado, inúmeros alunos revelam dificuldades de aprendizagem sem apresentarem qualquer tipo de deficiência. Ambos, contudo, possuem NEEs, exigindo recursos que não são utilizados para os demais alunos, além de medidas preventivas para evitar que a própria escola origine dificuldades relativas ao seu desenvolvimento cognitivo, afetivo e social (Brasil, 2005).

A esse respeito, Fernández (1991) considera que:

[...] a deficiência intelectual não implica necessariamente problema de aprendizagem, ainda que possa ser um condicionante, dependendo de como a família (signifique) o dano intelectual. Aceitando e querendo ao deficiente, permitir-se-á que alcance o máximo de suas possibilidades (portanto, que não some à deficiência um problema de aprendizagem). (p. 38)

Weiss (1997), por seu turno, alerta para o perigo de um diagnóstico precipitado, em que as condiçóes sociais precárias podem ser indevidamente rotuladas como uma deficiência mental.

Logo,

[...] não se podem desconsiderar as relaçóes significativas existentes entre a produção escolar e as oportunidades reais que determinada sociedade possibilita aos representantes das diversas classes sociais. Assim, alunos de escolas públicas brasileiras provenientes das camadas de mais baixa renda da população são frequentemente incluídos em classes escolares especiais, considerados pertencentes ao grupo de possíveis deficientes mentais, com limites e problemas graves de 
aprendizagem. $\mathrm{Na}$ realidade, faltam-lhes oportunidades de crescimento cultural, de rápida construção cognitiva e desenvolvimento da linguagem que lhes permita maior imersão num meio letrado [...]. (p. 16)

Desse modo, observa-se que o diagnóstico pedagógico tem testemunhado uma gradual evolução conceitual: de uma posição eminentemente clínico-patológica a uma concepçáo mais ampla e voltada para as potencialidades do aprendiz. O resultado da intervenção pedagógica atua como a função norteadora da avaliação diagnóstica, promovendo, dessa forma, uma contínua retroalimentação. Portanto, pode-se afirmar que o diagnóstico favorece a intervenção, pois modifica e potencializa as situaçóes favoráveis à aprendizagem. Pode colaborar, de modo análogo, para o reconhecimento social das potencialidades do educando com NEEs.

\subsection{A avaliaçáo da aprendizagem para alunos com NEEs}

Há muito tempo, tenta-se explicar o fracasso escolar como um problema exclusivamente do aluno ou da família. Essa interpretação, ainda vigente nos meios escolares, tenta justificar o emprego da avaliação da aprendizagem numa tradicional e incongruente perspectiva classificatória. São arrolados como fatores causais do insucesso escolar: as condiçóes socioeconômicas da família, a influência do seu meio cultural e o patrimônio genético do indivíduo (André, 1999; Fernández, 1991; Weiss, 1997).

Na concepção de André (1999), apesar da existência de indícios que relacionem o nível socioeconômico familiar ao desempenho do aluno, cada família possui uma cultura particular, uma forma de se organizar e de funcionar que apresenta mais influência sobre a aprendizagem do que o nível social em si. Dessa forma, elementos como o modo de vida de uma família, seus valores, crenças e opções, seus meios de interagir e de se comportar incidem de modo mais significativo sobre o desempenho escolar do que simplesmente o seu nível socioeconômico.

Além dessas reflexóes, devemos considerar os aspectos relacionados à organização e ao funcionamento das práticas escolares dentro da própria instituição. Para os estudantes que apresentam NEEs, há a necessidade de instrumentos pedagógicos adequados às suas particularidades. A escola deveria acolher essas diferentes maneiras de aprender e delas retirar proveito, em vez de excluir aqueles que se desviam das expectativas comuns.

O fato de existir uma nota mínima exigida para a promoção, por exemplo, já é um reflexo de que a escola continua adotando padróes uniformes e conservadores 
de avaliação. A nota mínima representa a intenção de que alguma padronização é necessária na escola, sendo o rendimento mínimo, portanto, um requisito prévio, essencial, indispensável e de caráter generalizado, visto ser esperado de todos os alunos. Nesse momento, começam as exclusóes, para alunos com ou sem NEEs. $\mathrm{Na}$ acepção de Mantoan (2007), "[...] é urgente substituir o caráter classificatório da avaliação escolar, através de notas e provas, por um processo que deverá ser contínuo e qualitativo, visando depurar o ensino e torná-lo cada vez mais adequado e eficiente à aprendizagem de todos os alunos" (p. 50).

Segundo a Resolução no 2 de 11 de setembro de 2001, que institui as Diretrizes Nacionais para a Educação Especial na Educação Básica (Brasil, 2001),

Art. $6^{\circ}$ Para a identificação das necessidades educacionais especiais dos alunos e a tomada de decisóes quanto ao atendimento necessário, a escola deve realizar, com assessoramento técnico, avaliação do aluno no processo de ensino e aprendizagem, contando, para tal, com:

I - a experiência de seu corpo docente, seus diretores, coordenadores, orientadores e supervisores educacionais;

II - o setor responsável pela educação especial do respectivo sistema;

III - a colaboração da família e a cooperação dos serviços de Saúde, Assistência Social, Trabalho, Justiça e Esporte, bem como do Ministério Público, quando necessário. (p.70)

Conforme estipulam essas diretrizes, avaliar a aprendizagem de alunos com NEEs constitui uma ação abrangente, com a extensão dessa responsabilidade a todos os atores da prática pedagógica. São necessárias, ainda, modificações no sentido de tornar essa avaliaçáo promotora da aprendizagem e inclusiva, em vez de ameaçadora e excludente.

Com propriedade, Luckesi (2005) substitui a expressão “juízo de valor” por “juízo de qualidade”, dada a associaçáo estabelecida entre valor e mensuração. Desse modo, critica a avaliaçáo da aprendizagem com o objetivo de aferir o rendimento escolar do aluno por meio da atribuição de valores que supostamente possam medir o que ele aprendeu, delimitando sua promoção ou reprovação. Essa possição tem configurado uma pedagogia do exame, que passou a direcionar a prática educativa escolar; nesse contexto, a avaliação perde o sentido de avaliar a aprendizagem para se tornar um meio de disciplina e puniçáo: "Os professores utilizam as provas como instrumentos de ameaça e tortura prévia dos alunos, argumentando ser um elemento motivador de aprendizagem" (p. 18). 
De maneira análoga, Perrenoud (1999) assinala a presença de duas lógicas no emprego da avaliação: a serviço da seleção ou da aprendizagem. A seleção - diretamente associada à classificação - contribui para consolidar uma hierarquia de excelência. Uma avaliação a serviço da aprendizagem permite subsidiar o processo decisório em favor de intervençóes pedagógicas diferenciadas, com base nas necessidades dos alunos.

A presença de alunos com NEEs em sala de aula é um fator determinante para o redimensionamento das práticas avaliativas, especialmente quando suas limitaçóes são muito específicas, como no caso de alunos surdos, cegos, com problemas motores, intelectuais e comportamentais. A distribuição do espaço físico e a disposição do mobiliário, a organização do tempo e a divisão de grupos de trabalho, o planejamento das atividades de ensino-aprendizagem e dos recursos materiais e humanos devem ser favoráveis à participação dos alunos e ao desenvolvimento pleno de suas capacidades (Blanco, 1995).

Em relação à deficiência, Beyer (2005) identifica cinco paradigmas: i) clínicomédico; ii) sistêmico; iii) sociológico; iv) crítico-materialista; e v) da educação inclusiva. Para cada concepção, esclarece o modelo de avaliação adotado.

No paradigma clínico-médico, a avaliaçáo, efetuada por meio da anamnese ou história clínica, incide sobre os déficits e limitaçôes do sujeito, colaborando decisivamente para o encaminhamento do aluno a escolas especiais, em que os recursos terapêuticos predominam sobre a ação pedagógica. Na concepção sistêmica, são ponderadas as demandas curriculares, sendo a avaliação seletiva e disjuntiva, com o intuito de oferecer um programa curricular adequado mediante encaminhamentos para a escola regular ou especial, conforme o caso.

No paradigma sociológico, a deficiência é interpretada por meio da reação do grupo social, que pode agravar (por incompreensão ou preconceito) ou facilitar (por empatia ou compreensão) o desenvolvimento integral do indivíduo. Como ser social, os valores pessoais do professor são refletidos na forma de avaliar o aluno e nas expectativas acerca de sua aprendizagem. A visão crítico-materialista, fundamentada na sociedade de classes, concebe a inaptidão produtiva como resultado direto da deficiência, sendo a avaliação um modo efetivo de excluir o deficiente do mercado de trabalho.

O paradigma da educação inclusiva almeja superar preconceitos e barreiras atitudinais por meio da inclusão social da pessoa com NEEs. Nesse sentido, os focos da avaliação são deslocados: da seleção e encaminhamento a escolas especiais para a identificação das NEEs desse alunado e seu atendimento em escola regular; dos 
métodos quantitativos e normativos para a descrição qualitativa e a consideração do contexto social em que o indivíduo está inserido.

Adaptações metodológicas são também necessárias para os estudantes com altas habilidades/superdotação, autismo e TDAH. O aluno com altas habilidades/superdotação necessita de metodologia de ensino e avaliaçáo baseadas na criatividade, de modo a estimular suas capacidades. Os métodos pedagógicos tradicionais costumam desmotivá-lo a aprender, com o risco, inclusive, de sua evasão escolar. A ideia, ainda disseminada nos meios educacionais, de que esse aprendiz evolui sozinho e sem apoio constitui um mito e sobretudo uma desculpa para os profissionais se eximirem da responsabilidade e do desafio de educá-los (Brasil, 1999; Viana, 2005).

No que se refere ao aluno autista, o princípio de pleno desesenvolvimento de suas capacidades também é aplicado, com o acréscimo de intervençôes voltadas para a melhoria da qualidade das relaçôes sociais. Assim, deve-se favorecer o equilíbrio pessoal e o bem-estar emocional, bem como aproximar as crianças autistas de relaçóes humanas significativas. Nesse contexto, a função do professor consiste em proporcionar instrumentos funcionais conforme as possibilidades e limitaçôes da criança, com modelos e ambientes educacionais bastante estruturados (Rivière, 1995).

Para promover a verdadeira aprendizagem, Rivière (1995, p.288) afirma que o professor do aluno autista necessita seguir os seguintes passos: i) a organizaçáo do ambiente deve adequar-se à necessidade de estimular a atenção da criança e evitar sua distraçáo em relação aos aspectos relevantes das tarefas educacionais; ii) as instruçóes e sinais devem ser claros, simples, consistentes e adequados às tarefas, sendo apresentados somente depois de se assegurar a atenção do aprendiz; iii) dado o comprometimento da motivaçáo social, pela dificuldade das relaçóes interpessoais, deve-se trabalhar também com motivações de outra natureza - lúdica, social, comunicativa, sensorial - que o professor deverá descobrir e empregar, sistematicamente, para promover a aprendizagem. A avaliaçáo da aprendizagem de natureza diagnóstica é importante para identificar as capacidades do aluno autista e elaborar estratégias de ensino mais eficazes.

Os alunos com TDAH apresentam dificuldades no processamento das informações, que comprometem as faculdades cognitivas de atenção e memória, bem como a motivação para aprender. Tendo por objetivo adequar o processo de ensino e aprendizagem às reais capacidades desses alunos, o professor precisa criar e manter um ambiente estruturado e estável, informando o aprendiz sobre os objetivos concretos das tarefas, mediante instruçóes náo somente orais, mas também visuais. Importam, do mesmo modo, a disposição das cadeiras em fileira, o estabelecimen- 
to de rotina com regras da sala, períodos curtos para a realização de tarefas, como também a alternância do exercício intelectual e físico, permitindo, assim, a movimentação regular do aluno. As metodologias de ensino e avaliação devem enfatizar estratégias atencionais, com o uso de: frases curtas, claras e objetivas; conceitoschave; pausas periódicas durante as explicações e organização das informaçóes com os conhecimentos já construídos pelo aluno (Alencar, 2006).

Diante do exposto, pode-se observar que, dentre os elementos que definem o processo de ensino e de aprendizagem, a avaliação permite diagnosticar estratégias bem e malsucedidas, avanços e dificuldades, de modo a reorganizar as atividades pedagógicas. Assim, por intermédio da avaliação, o professor pode acompanhar o processo de aprendizagem dos alunos, e, ao mesmo tempo, monitorar sua prática profissional, realizando, dessa forma, uma investigação didática. De acordo com André (1999), a forma de conceber a avaliação permite elaborar hipóteses sobre a eficácia da ação docente, pois é pela avaliação da aprendizagem que verificamos se essa ação promove ou não a construção do conhecimento.

A escola precisa acolher e cumprir sua missão de educar os alunos com NEEs, adaptando-se às suas peculiaridades no campo da aprendizagem. Dessa forma, a avaliação torna-se inclusiva, na medida em que, ao invés de centrar-se nas limitaçóes desse alunado, direciona-se para o atendimento de suas necessidades e para a participação ativa de toda a comunidade escolar nesse sentido.

\section{CONCLUSÃO}

A avaliação diagnóstica apresenta forte influência para o avanço da aprendizagem e da inteligência, diante da superaçáo de desafios em diferentes áreas do saber e do fazer. O educador, em sala de aula, deve implementar estratégias pedagógicas a fim de evitar o desperdício do potencial humano, imprescindível para os tempos atuais, caracterizados pela sociedade da informação, sendo o conhecimento fonte de riqueza continuamente renovada (Pozo, 2002; Viana, 2005).

Por conseguinte, é preciso considerar as diversas situações em que a aprendizagem se manifesta, de acordo com suas necessidades básicas, inclinaçóes e anseios. Para além da dimensáo cognitiva, deve-se almejar a totalidade do sujeito, propiciando condiçôes para seu crescimento e melhoria como pessoa.

É necessário que se espere o máximo de aprendizado dos conteúdos curriculares ministrados, mas respeitando-se as limitaçóes naturais de todos os alunos, com ou sem NEEs. A forma tradicional de avaliar não considera esses limites e colabora para que o aluno fique retido por não aprender, o que é injustificado, incoerente e incons- 
titucional. A experiência demonstra que a repetência não constitui fator promotor da aprendizagem, mas sim o estímulo contínuo e a valorização das potencialidades discentes. Cada ano letivo configura uma nova oportunidade de aprendizado, e os conteúdos devem ser oferecidos de forma rica e plural, para que todos os alunos se identifiquem e aprendam a seu modo.

Apesar dessas consideraçóes, ainda persistem dificuldades no que se refere à adequada elaboração de recursos instrumentais para uma modalidade de avaliaçáo capaz de contribuir para o crescimento e a autonomia dos estudantes. $\mathrm{O}$ aluno com NEEs já experimentou os mais variados fracassos acadêmicos, sentindo, muitas vezes, serem seus esforços inúteis e duvidando, freqüentemente, de suas habilidades. Por esse motivo, o professor deve empenhar-se para modificar a suposta história de fracassos anteriores do aluno, estabelecendo laços entre suas capacidades e o rendimento escolar.

\section{REFERÊNCIAS BIBLIOGRÁFICAS}

ALENCAR, E. S. Psicologia e educação do superdotado. São Paulo: EPU, 1986.

ALENCAR, M. J. Q. Avaliar as estratégias de ensino ascensionais na prática do professor de crianças com transtorno do déficit de atenção/hiperatividade. In: CONGRESSO INTERNACIONALDEAVALIAÇÃOEDUCACIONAL, 3०, 2006, Fortaleza. Anais... Fortaleza: Imprensa Universitária, 2006. p. 43-61.

ALENCAR, M. L. Alunos com necessidades educacionais especiais: análise conceitual e implicações pedagógicas. In: MAGALHÃES, R. C. B. P. Reflexões sobre a diferença: uma introdução à educação especial. Fortaleza: Demócrito Rocha, 2003. p. 85-91.

ANASTASI, A.; URBINA, S. Testagem psicológica. Porto Alegre: Artmed, 2000.

ANDRÉ, M. Pedagogia das diferenças. In: ANDRÉ, M. (Org.). Pedagogia das diferenças na sala de aula. Campinas: Papirus, 1999. p. 11-26. BEYER, H. O. Inclusão e avaliação na escola de alunos com necessidades educacionais especiais. Porto Alegre: Mediação, 2005.

BLANCO, R. Inovação e recursos educacionais na sala de aula. In: COOL, C.; PALÁCIOS, J.; MARCHESI, A. (Org.). Desenvolvimento psicológico e educação: necessidades educacionais especiais e aprendizagem escolar. Porto Alegre: Artmed, 1995. v. 3, p. 309-318.

BRASIL. Ministério da Educação. Diretrizes nacionais para a educação especial na educação básica. Brasília: MEC, 2001.

- Política nacional de educação especial na perspectiva da educação inclusiva. Brasília: MEC, 2008.

- Programa de capacitação de recursos humanos do Ensino Fundamental: superdotação e talento. Brasília: MEC, 1999. 1 v., fasc. V-VII.

- Saberes e práticas da inclusão: avaliação para identificação das necessidades educacionais especiais. Brasília: MEC, 2005.

FERNÁNDEZ, Alicia. A Inteligência aprisionada: abordagem psicopedagógica clínica da criança e sua família. Porto Alegre: Artmed, 1991.

FERNÁNDEZ CABEZAS, Cristina de la Caridad. El Diagnóstico psicopedagógico en la prática educativa.In:CELAEE;UECE.Antologíaevaluación y diagnóstico. Fortaleza, 2000. p.31-37.

HADJI, C. Avaliação desmistificada. Porto Alegre: Artmed, 2001.

HERRERO, M. J. P. Educação de alunos com necessidades especiais: bases psicológicas. Bauru: EDUSC, 2000. 
HOFFMANN, J. Avaliar para promover: as setas do caminho. Porto Alegre: Mediação, 2001.

LAGE, A. M. V. O Portador de condutas típicas. In: MAGALHÃES, R. C. B. P. Reflexões sobre a diferença: uma introdução à educação especial. Fortaleza: Edições Demócrito Rocha, 2003. p. 152-159.

LAGE, A. M. V. et al. Capacitação de professores comopré-requisito para repensaroatendimento aos portadores de altas habilidades. In: CONFERÊNCIA INTERNACIONAL AVALIAÇÃO PSICOLÓGICA: FORMAS E CONTEXTOS, 70, 1999, Braga. Anais... Braga: APPORT, 1999. p. 176-179.

LUCKESI, C. C. Avaliação da aprendizagem escolar. São Paulo: Cortez, 2005.

MAGALHÃES, R. C. B. (Org.). Reflexões sobre a diferença: uma introdução à educação especial. Fortaleza: Demócrito Rocha, 2003.

MANTOAN, M. T. E. Educação inclusiva: orientações pedagógicas. In: BRASIL. Ministério da Educação. Atendimento educacional especializado: aspectos legais e orientações pedagógicas. Brasília: SEESP, 2007.

PERRENOUD, P. Avaliação: da excelência à regulação das aprendizagens entre duas lógicas. Porto Alegre: Artmed, 1999.

POZO, J. I. Aprendizes e mestres: a nova cultura de aprendizagem. Porto Alegre: Artmed, 2002.

RIVIÈRE, A. O Desenvolvimento e a educação da criança autista. In: COLL, C., PALACIOS, J., MARCHESI,A.(Org.)Desenvolvimentopsicológico e educação: necessidades educativas especiais e aprendizagem escolar. Porto Alegre: Artmed, 1995. v. 3, p. 272 - 291.

VIANA, T. V. Proposta de identificação de crianças portadoras de altas habilidades: estudo em escolas públicas no município de Fortaleza. 2005. 284 f. Tese (Doutorado em Educação) Faculdade de Educação FACED, Universidade Federal do Ceará.

WEISS, M. L. L. Psicopedagogia clínica: uma visão diagnóstica dos problemas de aprendizagem escolar. 4. ed. Rio de Janeiro: DP\&A, 1997.

Recebido em: fevereiro 2009

Aprovado para publicação em: junho 2009 